\title{
Editorial
}

\section{WORDS OF PROFESSOR DR. DOMINGO M. BRAILE}

$\mathrm{T}$ he electronic version in English of the Brazilian Journal of Cardiovascular Surgery - Revista Brasileira de Cirurgia Cardiovascular (RBCCV), available at the link http://www.scielo.br/rbccv, evoked great repercussions not only in Brazil, but also internationally. The novelty was highlighted in the May and June electronic newsletters from CTSNet, a site that brings together the main publications from the field of cardiovascular and thoracic surgery from around the world.

We took the liberty of publishing letters sent to us by Bob Replogle, director and member of the editorial council of CTSNet and Tom Ferguson, editor of The Annals of Thoracic Surgery from 1984 to 2000 . Mr. Ferguson is also director and member of the editorial council of CTSNet. Both congratulated the Journal for its new phase.

Correspondence received:

Dear Dr Braile,

I want to congratulate you on the fine appearance of the Brazilian Journal of Cardiac surgery on CTSnet. It is remarkable how well it is done, and this communication will bring our professional communities much closer together. It seemed like a long time in coming, but you persisted and the effort is well worth it. You and your colleagues deserve much credit for this accomplishment. Nice going.

\section{Bob Replogle, MD}

Director and member of the editorial board of CTSNet

\section{My reply:}

\section{Dear Prof. Replogle}

Receiving an email like the one that you sent to $m e$, is a gift and a great incentive to continue to work hard with the "Brazilian Journal of
Cardiovascular Surgery". You know well, how difficult it is to keep our specialty on a high level in the present days, mainly in a developing country like Brazil. Even considering that, many colleagues are helping me in the "adventure" of producing a Journal at an international level here. Your kind words will represent a fantastic help to maintain our people even more interested in taking part in this important project to diffuse our work around the world. I agree when you said that the publication will be very important to keep our professional communities much closer together. I send you our eternal gratitude.

Personal warm regards

\section{Domingo Braile}

Correspondence received:

Dr Braile,

Please look on the CTSNet home page under Journals for the announcement about your journal. The same announcement will appear in the May Newsletter, which should go out tomorrow. Thank you for making this rich resource available to members of CTSNet worldwide.

Best regards to you,

Tom Ferguson, MD

Senior Editor

CTSNet

ats@msnotes.wustl.edu

\section{My reply:}

Dear Prof. Ferguson

Thank you very much for the permanent attention that you have given to our Society and now to the "Brazilian Journal of Cardiovascular Surgery". Be sure that your attitude represents for me a great incentive to continue working hard in the publication, in a way to maintain the international level which is present in all the sections 
of the CTSNet. I congratulate you for the fantastic work that you are developing as the Senior Editor of the CTSNet.

\section{My Warmest Regards}

\section{Domingo Braile \\ Editor of the "Brazilian Journal of Cardiovascular Surgery”}

We would also like to thank the warm manifestations of support sent by several of our Brazilian colleagues, both from inside the Brazilian Society of Cardiovascular Surgery (Sociedade Brasileira de Cirurgia Cardiovascular) and outside and from our advertisers, who give the indispensable financial support necessary to make the journal viable. We must stress that, more than the satisfaction of achieving one of our main objectives when we assumed the post of editor of the RBCCV in April 2002, our new situation fills us with responsibility.

We emphasize that the printed issue, with articles in Portuguese, continues to be fundamental for the divulging of a very-high standard of works of Brazilian professionals, fulfilling its function to take advances and new techniques to doctors, and students improving the survival rate and quality to the patients.

This encourages us to continue improving the Journal, in a way that it will become more beautiful and more agreeable to read, escaping from the stereotype that scientific publications have to be monotonous, only awakening the attention of those people closely linked to the area to which they are directed. We know that we are on the right track, in this aspect also, as the $\mathrm{RBCCV}$ received much praise from professionals from the area of communications (Journalists and people in advertising), experts used to dealing with large corporations.

However, the circulation of approximately 1500 copies always was and continues to be a limiting factor for the propagation of our works. This situation has been reverted by the presence of our publication on the Internet, thanks to the valuable support of the team from Scielo, infinitely multiplying the number of potential readers of the Brazilian Journal of Cardiovascular Surgery. These numbers become even more magnificent with the online version in English, as this language, as we previously stated, is understood by, literally hundreds of millions of people.

It is for this new public that we should direct our efforts but without forgetting our Brazilian roots. Thus, it is of fundamental importance to further improve the quality of the articles, according to the norms of the RBCCV, demonstrating the excellence of the Brazilian research and its practical applications, in spite of all the difficulties resulting from the stagnation of the economy seen over the last years. We wish to especially thank the collaboration dedicated by the associated editors of the editorial board and the ad hoc peer reviewers, who have not spared any effort to uphold the scientific standards within the proposed schedule.

On thanking the authors, we hope that our colleagues continue to collaborate with us by sending articles, criticisms and suggestions, all of which are always welcome, thereby helping us to develop positively. We count on the union of all and with the professional work of our support team, we are sure that we will continue the struggle to reach the coveted objectives, without ever relaxing.

\section{My affectionate wishes, \\ Domingo M. Braile \\ Editor RBCCV}

